\title{
Ultra-sound assisted nano Y- zeolite /Mn adsorbent to removed sulfur from crude oil
}

\author{
Dr.Tahseen Hameed khlaif ${ }^{a}$,salemjawadkadum ${ }^{\mathrm{b}}$,Ali Jaafar Lateef ${ }^{\mathrm{c}}$ \\ a,b,c Petroleum Engineering Department, Kerbala University, Karbala, Iraq

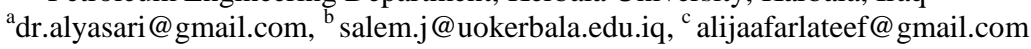

Article History: Received: 10 November 2020; Revised 12 January 2021 Accepted: 27 January 2021; Published online: 5 April 2021

\begin{abstract}
There are some types of crude oil that contains large quantities of various sulfur compounds that have great harm on the environment, oil economy, oil sector facilities such as fields and refineries.So developing ways to get rid of it is one of the most important goals of researchers in this sector. In this study, nanotechnology was used for environmentally friendly and available industrial materials (nano-zeolite Y), which can adsorb sulfur from crude oil, especially when it impregnated with manganese metals with ultrasound to increase the adsorption efficiency. The effect (temperature, adsorbent dose, Samples PH) was studied with ultrasound and without ultrasound.On the efficiency of removal had best results with ultrasound andit was found that this material is highly efficient in removing sulfur compounds, especially at a temperature of $100 \mathrm{C} \square$, and at a dose of $13 \mathrm{~g}$, and PH 7 it found the best adsorption efficiency about $99 \%$. The change in the properties of the adsorbent material is almost non-existent, with a change in the surface area and pore size.
\end{abstract}

Keywords: Ultra-sound, zeolite , sulfur, crude oil

\section{Introduction}

In many oil fields in the world oil extracted contains very high levels of sulfur with its various simple and complex compounds such as mercaptans, sulfates, and multiple sulfateswhich are the most complex and decomposing.Both these simple and complex compounds have a major impact on various fields. Therefore,it is of great importance to get rid of the various sulfur compounds (simple and complex) from crude oil and its derivatives (such as gasolinediesel and LPG) because of the danger it poses to these fluids. Where sulfur compounds are burned in the fueltoxic and sulfur oxide gases will be generated. Where when interacting with water in the atmosphere will be sulfate and acid rain that causes damage to buildings and the death of fish resources in lakes and rivers and acidification of the soilwhich in turn leads to great damage in nature in general and in plants in particular. The emission of sulfate gases has a major impact on human healthas it causes respiratory diseasesheart diseases and asthma[1]. On the industrial level, the presence of sulfur in crude oil causes corrosion for tankspipes and pumpsas well as refining columns in refineries[2]. On the economic level of crude oil, there is a big role for the percentage of sulfur it contains. When it decreasesit leads to higher prices and vice versa[3].Therefore,West Texas Intermediate and Brent Crude are the main international standard for crude oil in the world because they contain the least quantities of sulfur [4]. International regulations have determined the acceptable percentage of sulfur in crude oil varies from less than $0.05 \mathrm{wt} . \%$ to more than $14 \mathrm{wt} . \%$ depending on the source of crude oil[5]. And the sulfur content in transportation fuels such as gasoline and white oil should be less than $10 \mathrm{ppm}$ according to environmental regulations[6]. For the reasons mentioned abovethe processes of removing sulfur from crude oil is one of the most important issues for the petroleum sector. So there are many ways to remove sulfur compounds from crude oilincluding - Hydrosulfuration (HDS) method It is a chemical process used to remove sulfur from crude oil and its derivatives using the hydrogenation method and applied to natural gas and refined oilderivatives such as kerosene and diesel fuel .It has many difficult requirements for use including the pressure should be about $\quad\left(60 \_100 \mathrm{bar}\right)$ and the temperature around (250 _350) C [7].Oxidative desulfurization (ODS) if the compounds containing the aromatic sulfur are oxidized to their analog sulfate and have been confirmed as one of the effective desulfurization processes. (Tahseen and Asaad 2019) they concluded that the use of ultrasound in the desulfurization process has proven successful and has produced a high desulfurization efficiency from crude oil[8].Bio desulfurization (BDS) this technology is based on bacteriawhere bacteria remove organic sulfur from oily fractures without destroying the organic carbon structure of the compounds [9]. The efficiency of the process of removing sulfur by extracting with solvents has been studied withdifferent solvents that were used such as acetonitrileacetone and methanol. After 30 minutes'sulfur content was measured in the crude oil modelwhere acetonitrile showed high efficiency in extracting sulfur compounds compared to acetone and methanol where the removal efficiency was $28.5 \%$ and by Mixing 3: 1 solvent/oil[10]. These methods are effective in removing alpha-sulfur compounds such as sulfatesbut they are ineffective in 
removing aromatic sulfur compounds such as thiophene derivatives[11].Therefore,more effective methods must be devised to remove these compounds, and accordingly, some absorbing materials have been explored to remove sulfurspecifically zeolitewhich is environmentally friendly and also widely available and cheaphas selectivity and good adsorption capacity. To enhance this selectivity, the zeolite material is supplied with the introduction of selective metals such as $(\mathrm{Pd}, \mathrm{Mn}, \mathrm{Zn}, \mathrm{Ni}, \mathrm{Cu}, \mathrm{Ce})$ it is reported that the process of removing sulfur from crude oil using zeolite and adsorbed minerals is carried out using an exchange or impregnation method. In this regard, Yanget al. (2003) Mentioned that the (AgY) zeolite obtained by ion exchange is able and with high selectivity to adsorb sulfur compounds at high pressureand temperature conditions [12]. While song et al. (2003)mentioned that (CeY)zeolite has proven its ability to remove complex sulfur compounds with high efficiency[13]. Chenet al. (2009) proved that zeolite impregnated with $\mathrm{Cu}^{+}$was highly susceptible to removing thiophene sulfur compounds compared to zeolite impregnated with $\mathrm{Ag}^{+}$. This study also demonstrated that the adsorbent AgNo2 / MCM_41 is highly efficient in removing sulfur compounds from JP_5 Jet fuel (1172PPmws).[14]. We conclude from this that the presence of aromatic and alpha-sulfur substances in sulfur reduces the efficiency of the desulfurization process. In this regard, Sulfur adsorption was studied by Hua Song et al. (2015) for a sample of gasoline containing certain proportions of thermal sulfur compounds (thiophene and benzothiophene) by the intermediate material zeolite $\mathrm{Cu}$ (II) _ $\mathrm{Y}$ and $\mathrm{Cu}$ (IV) _ Y and the result of this study was that there is a high ability of these matrrials to remove sulfur compounds with high efficiency and high selectivity from gasoline [15]. Also, zeolite has good sulfur that contains capacitygood regeneration and stable structure. The adsorption process is the best separation process for sulfur from crude oil compared to other methods[16]. In our study, we usedNano zeolite type $\mathrm{Y}$ to extract sulfur from crude oil and by using Manganese ions to enhance the adsorption process for zeolite with using nanotechnologyand ultrasound as an alternative energy source.

\section{Experimental Work}

\section{1-Material and Equipments}

Fifteen samples of crude oil (100 ml / sample) was provided from Baba Gurgur oil field in the north of Iraq with it Properties in table 1, Synthetic Nano Zeolite (type Y) from CECA ARKEMA Group, Manganese (II)nitrate hydrate from the ALDRICH-United Kingdom, Ultrasound Device was purchased from Hans-Ulrich PetermannBeratungs, Germanywith power about 400watt and frequency about $24 \mathrm{kHz}$. Thermoshaker device from Heidolph with a speed of $1400 \mathrm{rpm}$ and Temperature of $300 \mathrm{C}^{\circ}$, Electrical oven with a temperature of $1000 \mathrm{C}$, Magnetic stirrer -German with a speed of $1500 \mathrm{rpm}$.

Table(1). Properties of crude oil sampls

\begin{tabular}{|c|c|c|}
\hline $\begin{array}{l}\text { Item } \\
\text { r\$asurment }\end{array}$ & $\begin{array}{l}\text { Measurement } \\
\text { Results }\end{array}$ & Unit of \\
\hline$\overline{1}$ & Water & cut \\
\hline 2 & Salt & PPM13 \\
\hline 3 & Sulfur & $\% 1.9$ \\
\hline 4 & API@60F & 35 \\
\hline 5 & Density @15 & $\overline{0} .849$ \\
\hline
\end{tabular}

\section{2-Procedure}

\subsection{1-Adsorbent Preparation.}

Firstly, we got a Beaker with $1000 \mathrm{ml}$ and we added 60 grams of Nano zeolite $\mathrm{Y}$ to it. After that, we added $666.36 \mathrm{ml}$ of Manganese Nitrate Solution $\mathrm{Mn}\left(\mathrm{NO}_{3}\right)_{2}[5 \mathrm{M}]$ for the impregnated percentage of $10 \%$. After that, we shake the Solution in Beaker for 3 hours in Temperature of $70 \mathrm{C}^{\circ}$ until the Nano zeolite absorbed fully by using an ultrasound device. The next step we did was washed the Adsorbed Nano zeolite Y with distilled water to remove the impurities and ions that stuck to it. After the washing process, we dried the washed Nano zeolite in the oven in Temperature of $25 \mathrm{C}^{\circ}$ and increase it until $100 \mathrm{C}^{\circ}$ for 4 hours.After the

drying process finished we started in the Calcination Process which is a thermal treatment process for Nano zeolite Y with air or Oxygen to remove the volatile practicals from it. The process was done by putting the Nano zeolite in the oven in Temperature of $500 \mathrm{C}^{\circ}$ for 3 hours. After the Calcination Process has done Sample of Nano zeolite $\mathrm{Y}$ became ready for testing on crude oil sample by Batch Experiment Paragraph[17]. 


\subsection{2-Characterization of adsorbents}

Nanomaterials have a high relative area (area/volume), so its surface area was calculated using the BET method by Nitrogen impregnation at $77 \mathrm{~K}$ and relative pressure (P / Po) about 0.95 and the results were about630.31 $\mathrm{m}^{2} /$ gsurface area and $14.37 \mathrm{~nm}^{3}$ pore volume and $2 \mathrm{~nm}$ pore radius. The samples were ground and each sample was placed on a silicon-carrying zero surface. Reflection data obtained using a diffractometer XRD_7000 with copper $\mathrm{K}_{\alpha}$ as a radioactive source with operating conditions of $40 \mathrm{~mA}$ and $40 \mathrm{kV}$. The scanning speed was within $0.04 / 0.25 \mathrm{~s}$ Within $\left(5^{\circ}{ }_{-} 75^{\circ}\right)$.

\subsection{3-Batch Experiments}

A fixed amount of the crude oil sample was mixed with an amount of about $(100 \mathrm{ml})$ with different quantities of Nano zeolite Y saturated with manganese minerals as shown in the table (2) with changing working conditions (PH, Time,Temperature, Dose) each time and several attempts.Mixing was done by a mixer device. The mixture was stirred with heat using

the Thermostat shaker device and ultrasound device. After the mixing step and the homogeneity of the mixture by heat, we separated the adsorbents that must be sulfur-bearing after the adsorption process ends with Nanofiltration paper to be isolated from the crude oil that must be sulfur-free or contain a very small percentage of it.Measurement of sulfur content in the samples was made by SPECTROSCAN SW-D3 "WDX.“

\begin{tabular}{|c|c|c|}
\hline \multicolumn{3}{|c|}{ Table(2).Samples used in experiments } \\
\hline Run No. & Variables & Constants \\
\hline $\begin{array}{l}1 \\
2 \\
3 \\
4 \\
5\end{array}$ & $\begin{array}{l}\text { Dosage } \\
5 \mathrm{~g} \\
7 \mathrm{~g} \\
9 \mathrm{~g} \\
11 \mathrm{~g} \\
13 \mathrm{~g}\end{array}$ & $\begin{array}{l}\text { Temp. } 90^{\circ} \mathrm{C} \\
\text { Time: } 3 \mathrm{hr} \text {. ( } 2 \mathrm{hr} \text { with } \\
\text { ultras ound }+1 \mathrm{hr} \text {. } \\
\text { without ultrasound) } \\
\text { PH:7 }\end{array}$ \\
\hline $\begin{array}{c}6 \\
7 \\
8 \\
9 \\
10\end{array}$ & $\begin{array}{l}\text { PH } \\
5 \\
6 \\
7 \\
8 \\
10\end{array}$ & $\begin{array}{l}\text { Dosage: } 13 \mathrm{~g} \\
\text { Time: } 3 \mathrm{hr} \text {. } \\
\text { (2hr.with } \\
\text { ultras ound }+1 \mathrm{hr} \text {.without } \\
\text { ultras ound) } \\
\text { Temp.: } 90^{\circ} \mathrm{C}\end{array}$ \\
\hline $\begin{array}{l}1 \\
2 \\
3 \\
4 \\
5\end{array}$ & $\begin{array}{l}\text { Temp. }{ }^{\circ} \mathrm{C} \\
60 \\
70 \\
80 \\
90 \\
100\end{array}$ & $\begin{array}{l}\text { Dosage: } 13 \mathrm{~g} \\
\text { Time: } 3 \mathrm{hr} \text {. } \\
\text { ( } 2 \mathrm{hr} \text { with } \\
\text { ultras ound }+1 \mathrm{hr} \text { without } \\
\text { ultras ound) } \\
\text { PH:7 }\end{array}$ \\
\hline
\end{tabular}

\section{Result and discussion}

\section{1-Adsorbent characterization}

Through XDR tests, it was observed that the change in the structure of zeolite is almost non-existent and is only a very slight change caused by impregnation of chemical metals during the ion exchange process, which led to an increase in the ratio of (silicon/aluminum) in the composition of zeolite from 3.22 to 3.24that mean increase of Silicon amount and it led to change catalytic active sites, thisthe aimof change (silicone/aluminum) ratio[18].Multiple BET checks of adsorbent samples adsorbed by nitrogen adsorption N2 and condensation inside poreshowed that the surface area increased from its initial pre-adsorption value of $630.31 \mathrm{~m}^{2} / \mathrm{g}$ to its new value after adsorption of $681.42 \mathrm{~m}^{2} / \mathrm{g}$ and it was also found that the volume of pores after the adsorption process increased its value from $14.37 \mathrm{~nm}^{3}$ to $16.84 \mathrm{~nm}^{3}$. The reason for the increase in both the surface area and the size of the pores is due to the impregnation it with metals[19], but after $950 \mathrm{C}^{\circ}$ as (Termal et al 2012) mentioned a decrease in pore volume and surface area when the temperature increase from $1176 \mathrm{C}^{\circ}$ to $1376 \mathrm{C}^{\circ}$ due to shattering walls of the pores due to the effect of increasing the temperature during the process[20]. 


\section{2-Dose effect}

The results showed that increasing the dose amount of the adsorbed materials in the crude oil sample increases the efficiency of adsorption and removing sulfur directly, as shown in Figure (1) without using ultrasound the best results at the high amount of dose $88 \%$ and $95.1 \%$ at $11 \mathrm{~g}$ and $13 \mathrm{~g}$ respectively. The best results with using ultrasound were $92.1 \%$ and $99.6 \%$ at $11 \mathrm{~g}$ and $13 \mathrm{~g}$ respectively. The reason for the increase in adsorption capacity and the decrease in sulfur amount when increasing the adsorbent dose is the decrease in concentration of sulfur, as the relationship between them and the adsorption dose is inverse, as shown in the following relationship.

Adsorption amount=(initial Conc. final Conc. $) \times($ volume / Adsorbent mass $)$

Furth more increased adsorption efficiency is increased accessibility to more surface binding sites when increasing the adsorption dose[21]. The reason for increase removal efficiency with using ultrasound as a thermal source is due to increase the temperature and pressure in a short duration compare with conventional thermal sources[22].Whereby doubling the dose amount by half of its initial value, the adsorption and desulfurization efficiency will increase by about $30 \%$, in addition to the percentage of the initial removal. And experiments showed that the use of the ultrasound device in the process of mixing and homogenizing the samples has a noticeable effect in increasing the removal rate.

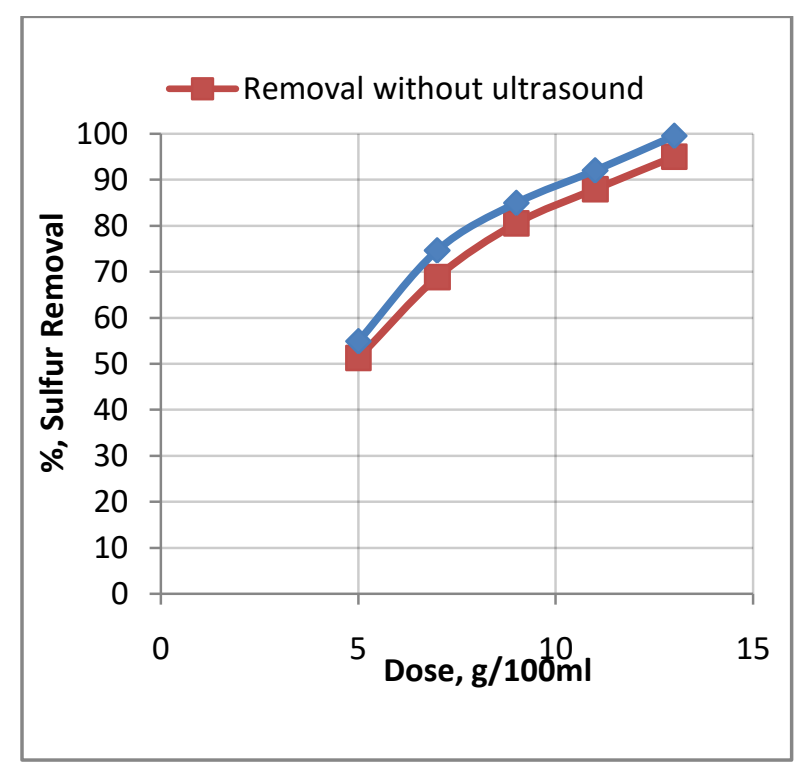

Figure (1)Effect of adsorbents dose on the Removal Efficiency of sulfur components (T:90 $\mathrm{C}^{\circ}$ and $\left.\mathrm{PH}: 7\right)$

\section{3-Temperature effect}

The results showed ,the increase in temperature has a direct effect on increasing the sulfur adsorption rate by adsorbents from crude oil. Best removal efficiency results we obtained it was $99.6 \%$ and $99.64 \%$ at $90 \mathrm{C}^{\circ}$ and $100 \mathrm{C}^{\circ}$ respectively. This is due to the increased rate of the chemical reaction between the solute (zeolite) and the solvent (sulfur in oil) that will cause changesin the adsorption sites and enhances their activities. Furthermore, when the temperature increases the favorable intermolecular forces between the adsorbents are much stronger than those between adsorbent and solvent. As a result, the temperature increasing causes adsorbent to be easier to adsorb [23]. The higher the temperature the viscosity of crude oil decreaseand sulfur rings will molecule into smaller rings then simple compounds were formed then these rings are easily broken, making the removal efficiency high[24].as (Basfar et al 2012) reported that DBT converted to $\mathrm{H}_{2} \mathrm{~S}$ at high temperature [25].while(Yu Zhao et al 2013) reported the reason of increase removal efficiency when temperature increased due to decrease of sulfur solubility and that made its removal easy.Also at high-temperature crude oil viscosity decreaseand its molecule's speed was increase and contact time between crude oil molecules and sulfur molecules was decreasetoo[26]. 


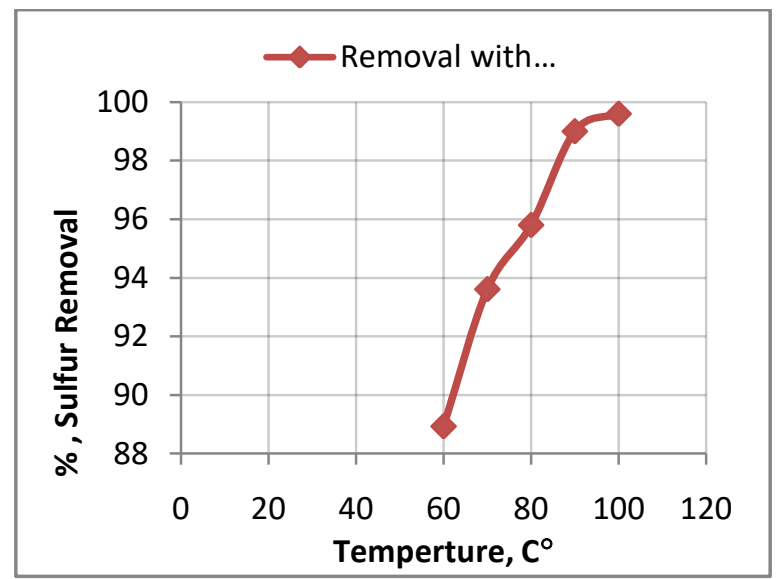

Figure (2)Effect of Temperature on the Removal of sulfur components (Dose:13g and PH:7)

\section{4-PH effect}

Through the results, it was found that the $\mathrm{pH}$ value of the crude oil samples below 7 affecteddirectly by the removal and adsorption of sulfur compounds, where when the $\mathrm{pH}$ (from 1-7) increased, the removal rate increased significantly, as in Figure (3). The best result was $99.6 \%$ at PH 7. The reason for this is that complex sulfur compounds break up into simple sulfur compounds such as sulfide [27].Also for PH values above 7(especially from 8-11) in crude oil showed good efficiency removal because crude oil hasmoderate alkalinity (PH from 9-11) this leads to a decrease in the concentration of sulfur in crude oil, thus increasing sulfur removal efficiency[28]. One of the reasons for increased adsorption efficiency in the PH incremental range of (1-7) is a change in active sites as the active sites increase in the acidic part and decrease as we get closer to the alkaline portion because the change in the $\mathrm{PH}$ value towards the alkaline portion affects the structure of the molecules and reduces their activity [29].

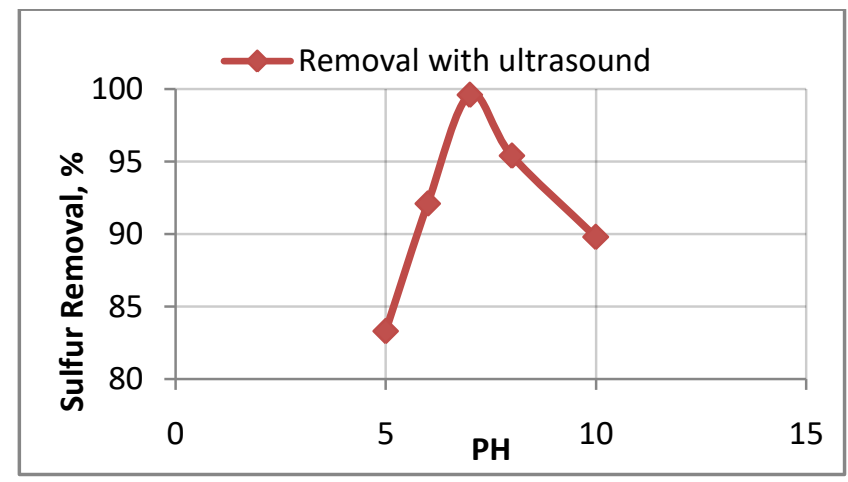

Figure (3)Effect of crude oil PH on the Removal Efficiency of sulfur components (T:90 $\mathrm{C}^{\circ}$ and Dose:13g)

\section{Conclusion}

Depending on the experiments conducted on crude oil samples, the following can be concluded:

-

When preparing adsorbents, it was found that when zeolites are kept for a long time and at high temperatures during the impregnation process, it can lead to a decrease the pores volumein the material as a result of the shattering of their walls.

-

The use of nanotechnology in the impregnation of particles of metallic materials with zeolite $\mathrm{Y}$ has increased the efficiency of saturation of zeolite with metallic materials compared to other techniques used in other studies.

- $\quad$ Increased temperature, adsorbent dose, adsorption time, and PH samples contributed significantly to adsorption and improved sulfur removal efficiency from crude oil.

- $\quad$ The high concentration of adsorbents improves sulfur absorption efficiency. The use of an ultrasound source in the homogenization process increased sulfur absorption and increased removal efficiency.

$\bullet$ Zeolite type Y has a higher sulfur removal efficiency than other types based on comparisons made with other studies.

The sulfur removal efficiency of crude oil increases when the adsorption time is increased at high temperatures. 


\section{References}

Australian Government, Department of Environment and Energy," Sulfur dioxide (SO2)“,(2005).

Suresh A. and Jagath K., ,"Fundamental Corrosive Properties of Crude Oils and their Effect on the FerrousMetals" Journal of Chemical Engineering \&Process Technology,(2018).

Wallenius Wilhelmsen, "Ben Hargreaves, Sulphur2020", The Oil Market and Fuel Prices, (2020).

Andrew H., The Balance," Understanding The Crude Oil Market",(2020).

Orr, W. L., Science Direct, "Geologic and geochemical controls on the distribution of hydrogen sulfide in natural gas",(1975).

Tawfik A. S. et al., , "Adsorptive desulfurization of thiophene,benzothiophene and dibenzothiophene over activated carbon manganeseoxide Nanocomposite: With column system evaluation"Cleaner Production Journal, (2017).

Tahseen H. K. and Assad S. B., ," Decreasing the Sulfur Content of Crude Oil by Ultra-Sound and Activated Carbon Assisted Oxidative Method",Materials Science and Engineerin,(2019).

Gary, J.H. and Handwerk G.E.,Marcel Dekker Journal, "Petroleum Refining Technologyand Economics",(1984).

Ghasemail M. and Andrew S., Science Direct, "Bio desulfurization of diesel fuels - Past, present and future perspectives", (2016).

Saja M., Research Gate,"Desulfurization of Al-Ahdab Crude Oil using Adsorption-Assisted Oxidative Process ", (2013).

Mehran S. and Argyrios M., Science Direct, "Bio Desulfurization of Refractory OrganicSulfur Compounds in Fossil Fuels",(2007).

Yang R. and Hernández A., Yang F.," Desulfurization of transportation fuels with zeolites under ambient conditions", (2003).

Song C.," An overview of new approaches to deep desulfurization for ultra-clean gasoline, diesel fuel and jet fuel", (2003).

Chen H. and Wang Y. and Frances H. Yang and Ralph T. Yang, ELSEVIER, " Desulfurization of high -Sulfur jet fuel by mesoporous $\pi$-complexation adsorbents ",(2009).

Hua S. and Youxin C. and Hualin S., Research Gate,"Deep adsorptive Desulfurization Over Cu, Ce Bimetal IonExchange Y-typed Molecule Sieve ",(2015).

Hassan Z. and Jeon J. and Jhung SH., Doi Organization, "Oxidative desulfurizatibenzothiophene and thiophene with WOx/ZrO2 catalysts: effect of calcination temperature of catalysts" ,(2012).

Tahseen H. K. Assad S. B.andMohammed D..”Sulfur Reduction of Crude Oil Using Zinc Oxide Nanoparticles Loaded Activated Carbon as Adsorben"Jornal of critical reviewVOL 7, ISSUE 17, (2020).

Abhay Suresh Zambare and John Ou and David Shan Hill Wong and ChiYaoaand Shi-Shang Jang," Controlling the product selectivity in the conversion of methanol to the feedstock for phenol production" ,(2019).

Pascal S. Thue, Eder C. Lima, Joseph M. Sieliechi, Caroline Saucier, Silvio L.P.Dias "Effects of first-row transition metals and impregnation ratios on the physicochemical properties of microwave-assisted activated carbons ",(2019).

Tremel, A., Haselsteiner, T., Nakonz, M., \&Spliethoff, H. Coal and char "properties in high temperature entrained flow gasifier. Energy", (2012).

kanlesh R. and Avinash G. and Dipesh S. "Deep-desulfurization of the petroleum diesel using the heterogeneous carboxyl functionalized poly-ionic liquid",(2016).

Rashad javadli and Arno deklerk"Desulfurization of heavy oil ",(2012).

Amir Hossein Kohsary"Influence of flotation parameters on decreasing sulfur and phosphorus content in the Gole-Gohar iron ore concentrate",(2011).

Oxford Butterworth Heinemann,Greenwood, N. N.; \& Earnshaw, A. ,(1997).

Basfar Ahmed and Mohamed Khalid "Method of removing sulfur crude oil and diesel using ionizing radiation",(2012).

Yu Zhao and Guoxin $\mathrm{Hu}$ "Removal of sulfur dioxide from flue gas using the sludge sodium humate ",(2013).

MashanBasafa and Kelly Hawboldt"Sulfur speciation in soured reservoir chemical equilibrium and kinetic " ,(2020).

Fu-Yan Go. and Eric-J. Hu "Effect of PH on rheological characteristics and stability ofpetroleum coke water slurry ", (2016).

Vania Battestin,"Effects of temperature, $\mathrm{pH}$ and additives on the activity of tannaseproduced by Paecilomycesvariotii",(2005). 